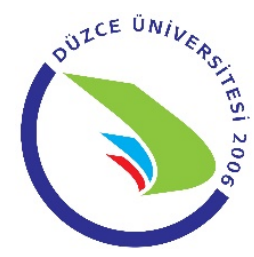

\title{
Anatomik Ön Çapraz Bağ Rekonstrüksiyonun Femoral Tünel Oblisitesi İle İlişskisinin Klinik Olarak Değerlendirilmesi*
}

\author{
Ozan TURHAL ${ }^{1}$, Zekeriya Okan KARADUMAN 國, Yalçın TURHAN ${ }^{2}{ }^{2}$, \\ Cemal GÜLER ${ }^{3}$, Șengül CANGÜR ${ }^{4}$, Mehmet ARICAN ${ }^{2}$
}

\begin{abstract}
ÖZ
Amaç: Artroskopik ön çapraz bağ (ÖÇB) rekonstrüksiyonlarında hamstring tendon grefti, patellar tendon grefti, allogreft gibi çeşitli tendon greftleri kullanılmaktadır. Çalışmamızda, Otojen Hamstring Tendonlar kullanılarak Anatomik Ön Çapraz Bağ Rekonstrüksiyonu uygulanan hastalarda femoral tünel oblisitesinin sonuçlarını güncel literatür eşliğinde değerlendirmeyi amaçladık.

Gereç ve Yöntemler: Ocak 2013 - Haziran 2016 tarihleri arasında ön çapraz bağ rüptürü nedeniyle kliniğimizde cerrahi olarak tedavi edilen hastalar telefonla aranarak hastaneye davet edildi. Bunlar içerisinden fizik muayeneleri, grafi kontrolleri ve ölçümleri yapılan 64 hasta çalışmaya dâhil edildi.

Bulgular: Hastalarımızın 55'i erkek, 9'u bayandı. Hastaların yaş ortalaması 29.3 \pm 8.12 (14-47) idi. Ortalama takip süremiz 14.47 \pm 7.44 (6-36) aydır. Kontrol Lysholm ve Tegner skoru ameliyat öncesi değerlerle karşılaştırıldığında istatistiksel açıdan ileri derecede anlamlı farkllılılar bulundu $(\mathrm{p}<0.001)$. International Knee Documentation Committee (IKDC) diz bağları değerlendirme sistemine göre ameliyat öncesi 3 hasta (\%4.7) B, 18 hasta (\%28.12) C ve 43 hasta (\%67.18) D olarak saptand. Ameliyat sonras1 yapılan son kontrol muayenesinde 41 hasta (\%64.06) A, 21 hasta (\%32.81) B ve 2 hasta (\%3.12) C grubuna dâhil edildi. Ortalama femur tüneli oblisitesi $41.2 \pm 7.2^{\circ}$ bulundu.

Sonuç: Ön çapraz bağ’ın rotasyonel stabilitesine oblik femoral tünel yerleşiminin daha fazla yarar sağladığı düşünülmektedir. Biz bu çalışmamızın sonucunda ön çapraz bağın otojen hamstring tendon grefti kullanarak anatomik teknikle uygulanmasının femoral tünel oblisite artışının fonksiyonel sonuca katkısının daha yararlı olduğu kanaatindeyiz.
\end{abstract}

Anahtar Kelimeler: Anterior cruciate ligaman yeniden yapılandırılmas1; rüptür; artroskopi.

\section{Clinical Evaluation of the Relationship of Anatomical Anterior Cruciate Ligament Reconstruction with Femoral Tunnel Obliquity}

\begin{abstract}
Aim: Various tendon grafts such as hamstring tendon graft, patellar tendon graft, allograft are used in arthroscopic anterior cruciate ligament (ACL) reconstructions. In our study, we aimed to evaluate in the light of the updated literature, femoral tunnel obliquity results of anterior cruciate ligament (ACL) reconstruction using autogenous hamstring tendon graft.

Material and Methods: Between January 2013 and June 2016, the surgically treated patients in our clinic who had anterior cruciate ligament (ACL) rupture were called and invited to hospital by telephone. 64 patients whose physical examinations, radiographs and measurements were completed have been included in the study.

Results: 55 of our patients were male and 9 were female. The mean age of the patients was 29.3 \pm 8.12 (14-47) years. Total follow-up time was $14.47 \pm 7.44$ (6-36) months. There were statistically significant difference between control and follow-up Lysholm and Tegner activity scores $(\mathrm{p}<0.001)$. According to the International Knee Documentation Committee (IKDC) knee ligation evaluation system, 3 patients (4.7\%) were B, 18 patients (28.12\%) were C and 43 patients (67.18\%) were revealed as $\mathrm{D}$ in preoperative term. In the last postoperative examination, 41 patients (64.06\%) were included in the group A, 21 patients (32.81\%) B and 2 patients (3.12\%) were included in the group C. The mean

1 Düzce Atatürk Devlet Hastanesi, Ortopedi ve Travmatoloji Bölümü, Düzce, Türkiye

2 Düzce Üniversitesi, Tıp Fakültesi, Ortopedi ve Travmatoloji A.D., Düzce, Türkiye

3 Çorum Hitit Üniversitesi, Tıp Fakültesi, Ortopedi ve Travmatoloji A.D., Çorum, Türkiye

4 Düzce Üniversitesi, Tıp Fakültesi, Biyoistatistik ve Tıbbi Bilişim A.D., Düzce, Türkiye

*Bu çalışma 24-29 Ekim 2017 tarihleri arasında Antalya'da düzenlenen 27. Ulusal Ortopedi ve Travmatoloji Kongresinde sözlü bildiri olarak sunulmuştur.

Sorumlu Yazar / Corresponding Author: Ozan TURHAL, e-mail: dr.ozn@hotmail.com

Geliş Tarihi / Received: 13.06.2019, Kabul Tarihi / Accepted: 02.08.2019
\end{abstract}


femoral tunnel obliquity was found as $41.2 \pm 7.2^{\circ}$.

Conclusion: The oblique femoral tunnel placement is thought to be of greater benefit to the rotational stability of the ACL. As a result of this study, we are of the opinion that the application of anterior cruciate ligament with an anatomical technique using an autogenous hamstring tendon graft is more beneficial to the functional outcome of femoral tunnel obliquity increase.

Keywords: Anterior cruciate ligament reconstruction; rupture; arthroscopy.

\section{GíRIS}

Ön çapraz bağ (ÖÇB) yaralanmalarındaki tartışmalar cerrahinin zamanlaması, greft seçimi ve en uygun cerrahi teknik üzerinde yoğunlaşmaktadır. Eklem içi (menisküs ve çapraz bağlar) ve eklem dışı unsurlar (kapsüller, bağlar, yan bağlar), eklemin mekanik aksı ve anatomisi diz stabilizasyonunda başlıca katkı sağlayan yapılardır. Stabilizasyonu sağlayan bu unsurlardaki herhangi bir yetersizlik dizin normal fonksiyonunu yerine getirmesinde engel olacaktır. Bundan dolayı ÖÇB tanı ve tedavisi günümüz spor cerrahisinin en önemli konularından biridir.

ÖÇB'nin başlica fonksiyonu tibianın anterior translasyonunu önlemek olup, tibial rotasyon, valgus ve varus streslerini de sınırlayıcı mekanik fonksiyonlarının yanında proprioseptif mekanizmada da önemli görev almaktadır (1). Tedavi edilmemiş ÖÇB yaralanmaları hastalarda dizde insitabilite yakınmasına sebep olarak hayat kalitesini bozmanın yanında sonrasında da erken yaşta osteoartrite ve ağrıya sebep olmaktadır $(2,3)$. Bu bağın rekonstrüksiyonundaki temel amaçlar, sporla uğraşan bireyler için dizin eklem hareket açıklığı ve stabilitesini spor yapabilir düzeye getirmek, aktif spor ile uğraşmayan bireyler için ise diz insitabilite yakınmasının önüne geçmek, eklem hareket açıklığını tekrar kazandırmak ve eklem artrozunu önlemektir.

\section{GEREÇ VE YÖNTEMLER}

$\mathrm{Bu}$ araştırma Düzce Üniversitesi Klinik Araştırmalar Etik Kurulu tarafindan kabul edilmiștir (2016/702). Bu çalışmada Ocak 2013-Haziran 2016 tarihleri arasında primer total ÖÇB rüptürü sebebiyle otojen hamstring tendon grefti kullanılarak anatomik ön çapraz bağ rekonstrüksiyonu yapılan 64 hasta retrospektif olarak değerlendirildi. Araştırmaya alınan toplam 64 bireyin 55'i erkek (\%86), 9'u (\%14) kadındı. Hastaların ameliyat sırasında ortalama yaşları 29'du. 35 hastada sağ taraf, 29 hastada sol taraf lezyonu mevcuttu. Operasyonların tamamı aynı cerrahi teknikle yapıldı. Hastaların hepsinde primer ÖÇB rüptürü olması ve otojen hamstring tendon grefti kullanılmasına dikkat edildi. Hastalarımıza öne çekmece, Lachman ve Pivot-Shift testleri muayene esnasında, anestezi altında ve operasyon sonras1 takiplerinde yapıldı. Hastalarımızın muayene bulgularına ek olarak MRG çekilerek bulgular doğrulandı. Lysholm skoru, Tegner aktivite skoru, IKDC değerlendirme formu bütün hastalarımıza ameliyat öncesi ve kontrol muayenelerinde dolduruldu. Ameliyat sonrası ön-arka radyografide femoral tünel ile eklem yüzeyine paralel bir çizgi arasındaki açı ölçülmüştür. Lateral radyografide femur tüneli ile femur şaftının arka korteksinin uzatma çizgisi arasındaki açı ölçüldü (Resim 1).

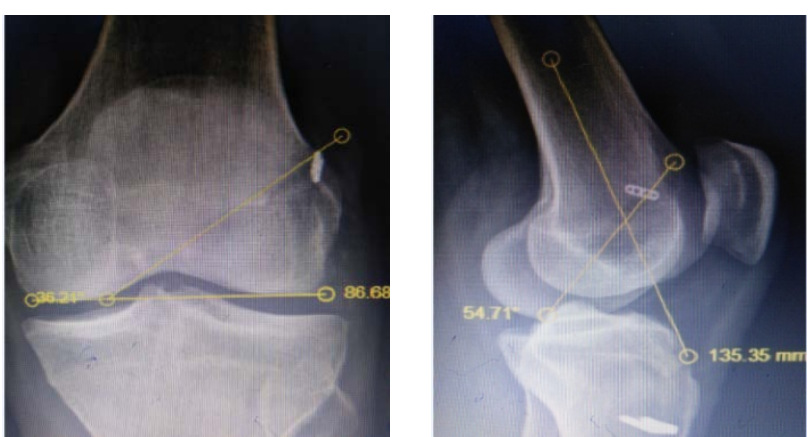

Resim 1. Femoral tünel oblisitesinin ap ve sagittal planda değerlendirilmesi

Hastaların ameliyat öncesi anestezi altında önce normal dizdeki tüm bağ testleri, sonra da sorunlu diz muayeneleri yapıldı. Hastalara ameliyat edilecek alt ekstremite tarafi hiperfleksiyona izin verecek şekilde pozisyon verildi. Ayrıca femoral tünel açılırken, ayak ameliyat esnasında masanın üzerine alınarak 120-130 derece fleksiyona izin verecek şekilde ameliyat pozisyonu dizayn edildi. Tüm hastalarımızda medial ve lateral tibia platosu ve femur kondilleri (eklem aralığı) patella, patellar tendon ve tibial tüberkül steril kalemle çizilerek işaretlendi. Cerrahi sırasında yüksek anterolateral portal (Y-ALP), aksesuar anteromedial portal (A-AMP) ve santral anteromedial portalin (S-AMP) açıldığı üç portal tekniği uygulandı (Resim 2).

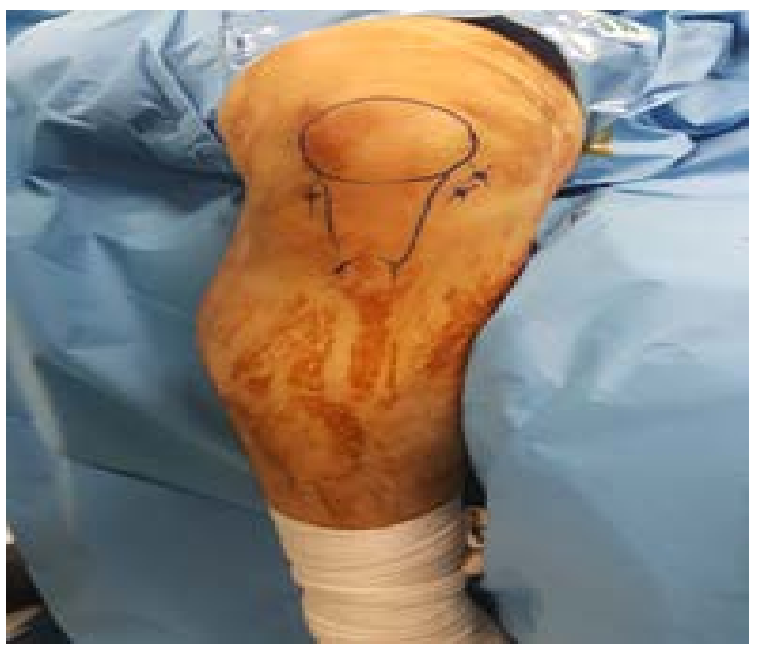

Resim 2. Y-ALP, A-AMP ve S-AMP açılma yerleri

Y-ALP asıl görüntüleme portalı olarak kullanıldı. AAMP'den prob ile ÖÇB, AÇB ve diğer diz 120-130 derece kadar hiperfleksiyona alınarak femoral ayak izinin tespiti için gerekli olan anatomik yapılar (ÖÇB artıkları ve kemik landmarklar) tespit edildikten sonra arthrocare veya shaver yardımıyla tünel giriş yeri temizlendi. Daha sonra femoral ayak izinin merkezine spinokan iğne ile giriş yapılarak aksesuar medial portalin yeri tespit edildi ve aksesuar AMP açıldı (Resim 3).

Daha sonra aksesuar medial portal kullanılarak işaret noktası üzerinden kılavuz tel lateralden çıkacak şekilde yerleştirildi. Diz maksimal hiperfleksiyondayken, anteromedial portalden femoral tünel görüntülenerek kılavuz tel üzerinden endobutton drili ile lateral femoral korteksi drillenerek femoral tünel açıldı (Resim 4). 


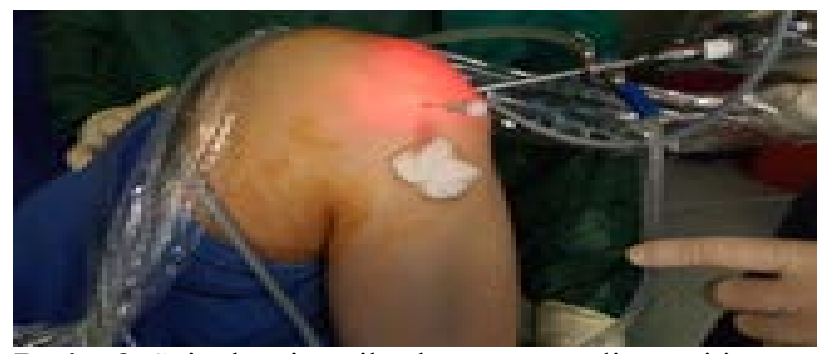

Resim 3. Spinokan iğne ile aksesuar portalin tespiti

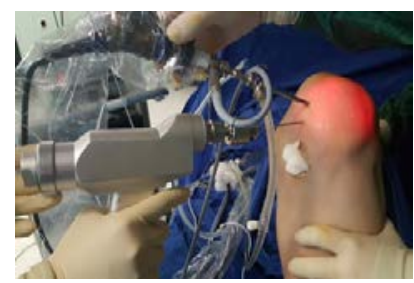

(a)

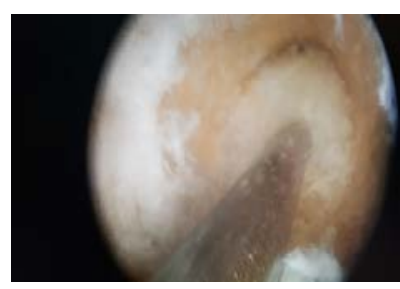

(b)
Resim 4. a -Femoral tünel oluşturulması 4. bArtroskopik femoral tünel görüntüsü

Guide-pin ve endobutton dirili çıkartılarak ölçü probu yardımıyla femoral tünelin boyu ölçüldü ve kaydedildi. Greftin boyu, çap1 ve kullanacağımız endobuttonun uzunluğu baz alınarak femoral tünel uygun drill boyu ile oyularak hazırland1. Daha sonra kılavuz tel üzerinden taşıyıcı sütur geçirilerek tibial tünel hazırlanmaya başladı. Femoral tünelin oluşturulması esnasında, aksesuar AMP'den eklem içine sokulan guide-pin, endobutton drili ve femoral drillerin medial femoral kondil eklem kıkırdağına zarar vermemesi için kamera ile enstrumanların medial femoral kondil arasındaki mesafe santal AMP'den görüntülenerek zarar verilmemesine özen gösterildi.

Tibial tünel başlangıcı olarak eklem çizgisinin $4 \mathrm{~cm}$ distali ve tibial tuberkulun 1-1.5 cm mediali tercih edildi. Ortalama $30 \mathrm{~mm}$ tibial tünel oluşturulmasına özen gösterildi. Tibial tünel hazırlanırken 55 derecelik tibial guide anteromedial portalden eklem içine yerleştirildi. Daha sonra guide üzerinden klavuz tel tibia çıkış noktasına doğru ilerletildi. Kılavuz telin intraartiküler çıkış yeri ÖÇB yapışma yerinin merkezinin birkaç mm posteriorunda olmasına dikkat edildi (Resim 5).

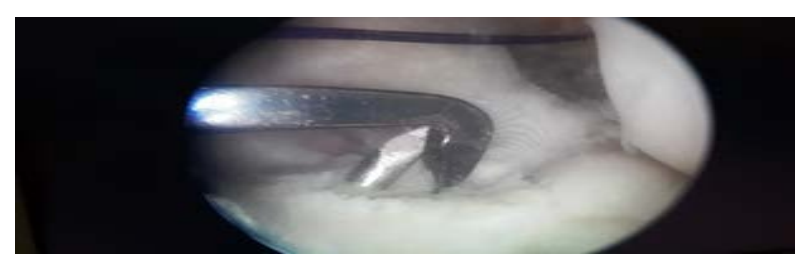

Resim 5. Tibial tünel oluşturulması

Eklem içinde kılavuz telin çıkış yerinin görünmesinin ardından diz tam ekstansiyona getirilerek konulacak greftin sıkışmaya neden olup olmayacağı değerlendirildi. Çıkış yeri sagittal plandada değerlendirilerek tibial guidden çıkartıldı ve kılavuz tel üzerinden greft çapına uygun drill gönderilerek tibial tünel hazırlandı. Bu aşamada intraartiküler yapılara zarar vermemek için kılavuz telin ucu küretle kontrol edildi. Daha sonra tutucu (grasping) yardımıyla femoral tünel içindeki sütur materyalinin loop yapılan kısmı tibial tünele taşındı ve endobutton sütürünü taşımak için hazır hale getirildi.
Greft tünellere yerleștirildikten sonra endobutton takla attırıldı ve tibial tünele uygun boyda biovida ile sabitlendi ve ardindan intraoperatif greft kontrol edildi (Resim 6). Greft kontrol edildikten sonra $8 \mathrm{~mm}$ u staple ile fikse edildi.

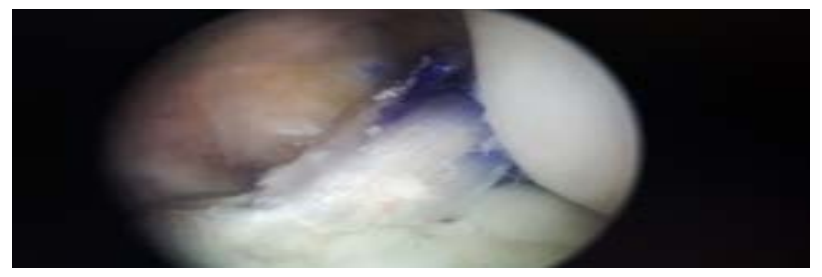

Resim 6. Greftin son halinin artroskopik görüntüsü

Tibial sabitlemenin ardından hastalarımızın hepsine öne çekmece testi ve lachman testi yapılarak dizin stabilitesi test edildi. Eklem içine kanül yerleştirilerek irrigasyonun ardindan bir adet hemovak dren konuldu. Operasyon esnasında yapilan insizyonlar anatomik usulüne uygun olacak şekilde kapatıldı ve pansuman yapıldı.

\section{İstatistiksel Analiz}

Çalışmadaki tüm verilerin tanımlayıcı istatistikleri hesapland1. Farklı periyotlarda ölçülen ölçüm değerleri arasındaki karşılaştırmalarda Wilcoxon sign ve Friedman testleri (post hoc Bonferroni correction Wilcoxon sign test) kullanıldı.

\section{BULGULAR}

Çalışmamız da 01.01.2013-01.06.2016 tarihleri arasında anatomik teknikle otojen hamstring tendon kullanılarak artroskopik ÖÇB rekonstrüksiyonu yapılan 64 hasta çalışmaya alındı. Çalışmaya dâhil edilen 64 hastaya femoral tespit yöntemi olarak endobutton kullanıldı. Hastaların 55'i erkek (\%85.9), 9'u kadın (\%14.1) idi. Hastaların 35'i sağ (\%54.7), 29'u sol (\%45.3) dizinde ÖÇB rüptürü mevcut idi. Hastanede yatış süresi, 1 ile 3 gün arasında değişmekteydi. Takip süreleri 6 ay ile 36 ay arasında değişmekteydi ve ortalama takip süresi 14.5 \pm 7.4 aydı. Hastaların yaşları ise en küçük 14 en büyük 47 ve ortalama 29.3 \pm 8.1 idi (Tablo 1).

Tablo 1. Hastaların demografik özellikleri

\begin{tabular}{|c|c|c|}
\hline & \multicolumn{2}{|c|}{$\begin{array}{c}\text { Ort } \pm \text { SS } \\
\text { Ortanca (Min-Maks) }\end{array}$} \\
\hline Yaş & \multicolumn{2}{|c|}{$\begin{array}{c}29.3 \pm 8.1 \\
28.5(14-47)\end{array}$} \\
\hline Takip Süresi & \multicolumn{2}{|c|}{$\begin{array}{l}14.5 \pm 7.4 \\
12(6-36)\end{array}$} \\
\hline & $\mathbf{n}$ & $\%$ \\
\hline \multicolumn{3}{|l|}{ Cinsiyet } \\
\hline Erkek & 55 & 85.9 \\
\hline Kadın & 9 & 14.1 \\
\hline \multicolumn{3}{|l|}{ Taraf } \\
\hline Săg & 35 & 54.7 \\
\hline Sol & 29 & 45.3 \\
\hline \multicolumn{3}{|l|}{ Etiyoloji } \\
\hline Diğer & 6 & 9.4 \\
\hline Basit Düşme & 3 & 4.7 \\
\hline İş Kazası & 3 & 4.7 \\
\hline Spor Yaralanması & 49 & 76.4 \\
\hline Travma & 2 & 3.2 \\
\hline Yüksekten Düşme & 1 & 1.6 \\
\hline
\end{tabular}




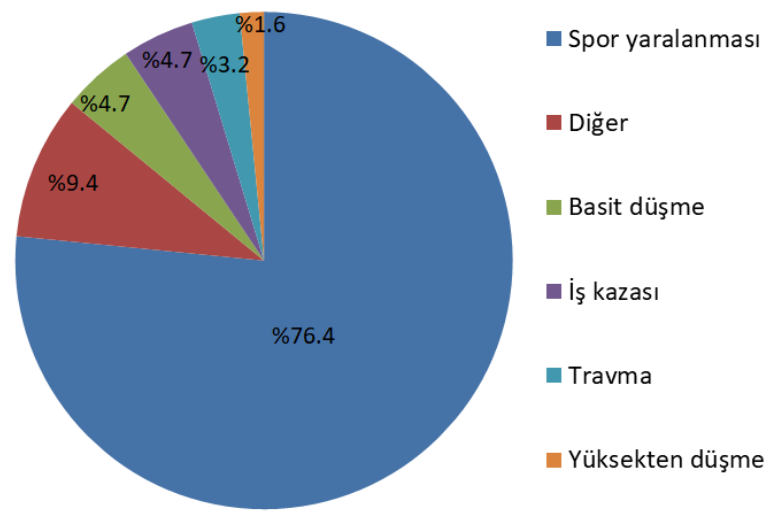

Grafik 1. Hastaların yaralanma etiyolojisinin dağılımı

Hastaların 49'u spor yaralanması (\%76.4), 6'sı diğer (\%9.4), 3'ü basit düşme (\% 4.7), 3'ü iş kazası (\% 4.7), 2’si travma (\% 3.2), 1'i yüksekten düşme (\% 1.6) sonrası yaralanmıştır (Grafik 1).

IKDC skoru operasyon öncesinde 3 hastada B, 18 hastada $\mathrm{C}$ ve 43 hastada ise D olarak bulundu. Ameliyat sonras1 yapılan 6. ay muayenesinde ise 41 hastada A, 21 hastada $B$ ve 2 hastada ise $C$ olarak değerlendirildi. Preop IKDC diz skor ölçüm değeri, postop IKDC diz skor değerinden anlamlı düzeyde daha düşüktü ( $\mathrm{p}<0.001$, Grafik 2).

Preoperatif lysholm skoru ortanca değeri 40 (Q1-Q2: 3844) ve ortalama değeri $40.58 \pm 4.92$ ile kötü olarak bulundu. Ameliyat sonrası ölçülen lysholm skoru ortanca değeri 78 (Q1-Q2: 72-78) ve ortalama değeri 73.75 \pm 9.93 ile orta olarak saptandı. Ameliyat sonrası 3. ayda ölçülen lysholm skoru ortanca değeri 84 (Q1-Q2: 82-86) ve

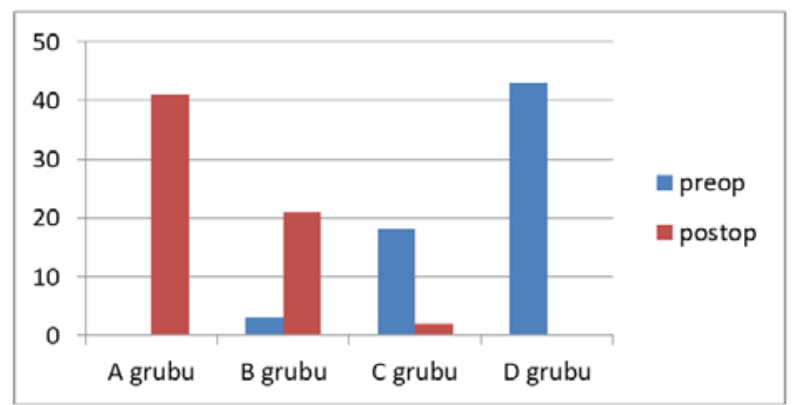

Grafik 2. Hastalarımızın IKDC gruplandırılması

ortalama değeri $84.06 \pm 4.13$ ile iyi sonuç bulundu. Yapılan son kontrol muayenesinde ölçülen lysholm skoru ortanca değeri 88 (Q1-Q2: 86-95.75) ve ortalama değeri $89.19 \pm 6.87$ ile mükemmel olarak saptandı. Farklı zaman periyotlarında ölçülen Lysholm skor ortanca değerleri arasında anlamlı düzeyde fark vardı $(\mathrm{p}<0.001)$. Bu anlamlı farklılık, tüm periyotların ikili saptandı (her biri için $\mathrm{p}<0.001$ Tablo 2).

Olguların preop dönemdeki Tegner skoru ortanca değeri 6 (Q1-Q2: 5-6) ve ortalama değeri 5.5 \pm 1.1 olarak bulundu. Ameliyat sonrası değerlendirmede ise Tegner skoru ortanca değeri 7 (Q1-Q2: 6-7) ve ortalama değeri $6.2 \pm 1.1$ olarak belirlendi. Tegner preop skor ortanca değeri postop değerinden anlamlı düzeyde daha düşüktü $(\mathrm{p}<0.001$ Tablo 3).

Tablo 2. Farklı zaman periyotlarında ölçülen Lysholm skor değerleri

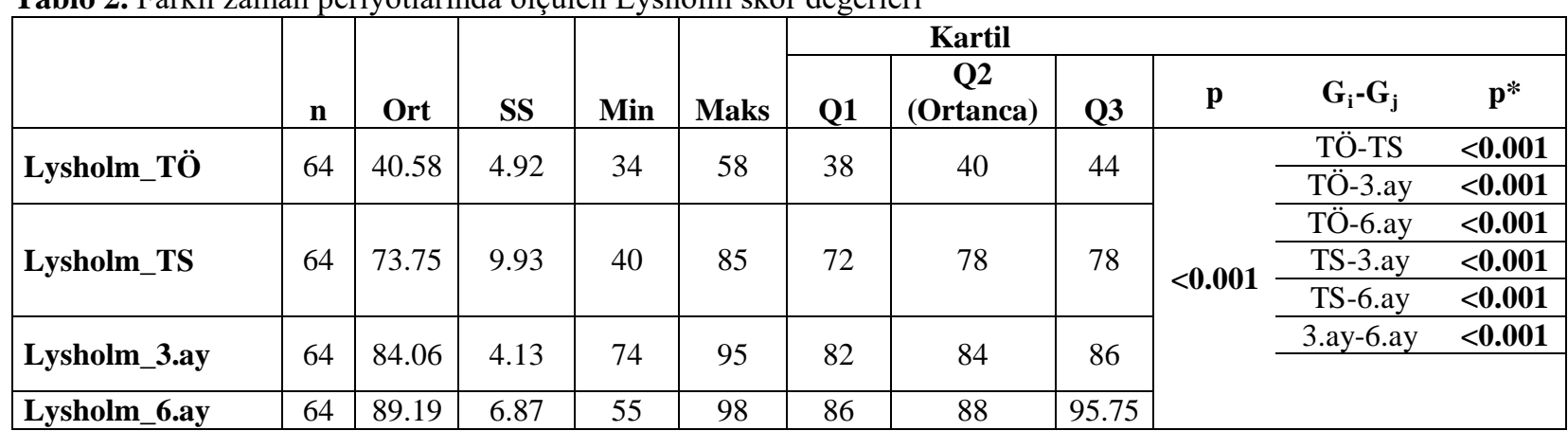

TÖ: Tedavi Öncesi, TS: Tedavi Sonrası, Ort: Ortalama, SS: Standart Sapma, Min: Minimum, Maks: Maksimum, Q1: 1. Kartil, Q3: 3. Kartil, $G_{i}-G_{j}$ : i. ve j. zamanların karşılaştırılması, $p^{*}$ : İkili karşılaştırmalar

Tablo 3. Farklı zaman periyotlarında ölçülen Tegner aktivite skor değerleri

\begin{tabular}{|c|c|c|c|c|c|c|c|c|c|}
\hline & & & & & & \multicolumn{3}{|c|}{ Kartil } & \multirow{2}{*}{ p } \\
\cline { 7 - 10 } & & Ort & SS & Min & Maks & Q1 & $\begin{array}{c}\text { Q2 } \\
\text { (Ortanca) }\end{array}$ & Q3 & \\
\hline Tegner_preop & 64 & 5.5 & 1.1 & 3 & 7 & 5 & 6 & 6 & \multirow{2}{*}{ (O).001 } \\
\hline Tegner_postop & 64 & 6.2 & 1.1 & 3 & 7 & 6 & 7 & 7 & \\
\hline
\end{tabular}

preop: operasyon öncesi, postop: operasyon sonrası, Ort: Ortalama, SS: Standart Sapma,

Min: Minimum, Maks: Maksimum, Q1: 1. Kartil, Q3: 3. Kartil 


\section{TARTIŞMA}

ACL, anteromedial ve posterolateral demetten oluşur. AM demeti temel olarak ön-ön stabilite ve posterolateral demetin rotasyonel stabiliteyi sağlamaktadır. Anatomik ÖÇB rekonstruksiyon tekniğinin koronal düzlemde yatay bir oblisite oluturmasının ön arka stabiliteye katkısının yanında rotasyonel stabiliteyi sağlaması güvenli bir yöntemdir.

Noyes'in (4) 84 hastalık çalışmasında; konservatif tedavinin sonucunda hastaların \%36'sı düzelmiş, \%32'si aynı kalmış ve \%32'sinde dejeneratif bulgular gelişmiştir. Ayrica diz bölgesinde aktif enfeksiyonu bulunan, obez, ileri yaş ve aktif spor yaşantısı olmayan durumlarda konservatif tedavi ana tedavi yöntemidir. Biz çalışmamızda ÖÇB yırtığı cerrahi tedavisindeki temel amacın hastalarımızın en ideal ve hızlı iyileşme sağlayarak günlük aktivite düzeyine ve spora başarılı şekilde dönüşünü sağladığını izledik.

ÖÇB cerrahi endikasyonları arasında kesin sınırlar bulunmamasına rağmen; sporcular ve aktif spor yaşantısına devam etmek isteyenler, ön çapraz bağın da dâhil olduğu çoklu bağ yaralanması ve menisküs yırtığ olan hastalar, günlük yaşamlarında instabilite tarif eden hastalar bulunmaktadırlar $(5,6)$. Bizim cerrahi olarak tedavi ettiğimiz hastalar literatür ile uyumlu cerrahi endikasyonlara sahipti. Daha önceleri cerrahi tedavide 45 yaş üstü ve epifizleri kapanmamış hastalar gibi yaş sınırı mevcutken artı günümüzde bu kriterler de değişmektedir. Böylece rekonstrüksiyonun sosyal açıdan gerekli olduğu durumlarda epifizler kapanmadan da uygulanmaktadır (7). Kliniğimize 18 yaş altı ve 45 yaş üstü iki hasta ameliyat edilmiş, bu hastalardan klinik olarak iyi sonuç alınmıştır.

Shelbourne ve arkadaşları (8), 169 genç atlet üzerinde yaptıkları çalışmada; yaralanmadan sonraki yedi gün içinde ÖÇBR uygulanan hastaların artrofibrozis gelişmesinin, cerrahinin üç hafta veya daha fazla geciktiği hastalara göre daha yatkın olduğunu tespit etmiştir. Bu çalışmada ilk 1 hafta içinde yapılan ÖÇBR sonrası fibrozis insidansı 21 günden sonra yapılandan yüksek bulunmuştur. Başka bir çalışmada ise 8-21 günler arası yapılan rekonstrüksiyonlarda hızlandırılmış rehabilitasyon da eklem sertliği görülmemiştir (9). Bu klasik çalışmaların ardından tahmini 3-6 hafta kadar bekleme süresi önerilmiştir.

Başka bir çalışmada ise Levy ve ark.'nın (10) meta analizinde, erken cerrahi ile geç cerrahi karşılaştırılmış ve erken cerrahi ile daha yüksek Lysholm skorları (90'a karşın 82), daha yüksek oranda IKDC diz skorları ve daha yüksek sportif aktivite skorları (89'a karşın 82) saptanmıştır. Ancak son yıllarda yapılan çalışmalarda artrofibrosiz riskinin yaralanmadan sonra geçen süreden çok dizin genel durumu ile ilgili olduğu gösterilmiştir (11). Son literatürler 1şı̆̆ında cerrahi zamanlamayı hemartroz varlığında aspirasyon yapılması, ağrının hafiflemesi ve eklem hareket açıklığının tam olarak yapıldığı dönem olarak belirtilmiştir (12). Vaishya ve arkadaşlarının (13) yaptığı bir çalışmada erken bir ÖÇBR'nin (yaralanmadan sonraki üç hafta içerisinde) artrofibrozis riski ile ilişkili olabileceğine dikkat çekilmekte olup yapılması durumunda, hızlandırılmış bir rehabilitasyon programı tarafindan desteklenmesi önerilmektedir. Biz de kliniğimizde cerrahi zamanlamayı güncel literatür ile uyumlu olarak, süreden ziyade hastaları ayrı ayrı değerlendirerek planladık. Biz dizdeki enflamasyon bulgularının düzeldikten hemen sonra erken cerrahi uygulanan hastalarda ek patolojinin daha az oluşacağı ve fonksiyonel sonuçların geç cerrahi uygulanan hastalara göre daha iyi olabileceği kanaatindeyiz.

Musil ve Sadovsky'e (14) göre Hamstring Tendonları patellar tendona göre patellofemoral morbiditesi bakımından daha üstündür. Ayrıca Darnley ve arkadaşlarının (12) yaptığı bir çalışmada bir gruba otogreft ve allogreftleri hibritleyerek bir gruba da sadece otogreft kullanarak grupları karşılaştırmış ve anlamlı fark bulamamıştır. Literatüre uygun olarak biz de kliniğimizde bütün hastalarımıza donör saha morbiditenin az olması, kolay uygulanabilmesi ve postoperatif komplikasyon oranının düşük olması ve dayanıklı greftlerin başında gelmesi sebebiyle dörde katlanmış ST, G tendonu kullandik.

ST ve G tendon grefti alınırken insizyona bağlı donör saha morbiditesi olan IPBSN (infrapatellar branch of the saphenous nerve) hasarıyla karşılaşılması söz konusudur (15). Oblik insizyonla greft alımı yapıldığında safen sinir dalının hasarı daha az riskli olduğu bildirilmiştir. Biz de vakalarımızda hem IPBSN'e zarar vermemek hem de tibial guide yerleştirirken ikinci bir insizyona gerek olmadığı için oblik insizyonu tercih ettik. Bir hastamızda IPBSN hasarına bağlı hipoestezi gelişti.

Wolf ve arkadaşları (16) notchplasti yapmadan ÖÇBR yapılan hastaları 2 sene takip etmişler ve greft yetmezliği ile karşılaşmamışlardır . Kliniğimizdeki genç hastalarda Notch mesafesini ölçmemizle birlikte femoral tünel yerleşimi için notchplasti ihtiyacı duymadık. Sadece femoral tünel yerleşimini doğru tespit için interkondiler notch'a ACL artıklarını temizlemek için shaver yardımıyla gerektiği kadar debritman yapıldı. Literatürle uyumlu olarak notchplasti işleminin daha çok osteoartritli dizlerde gerekliliğine inanmaktayız.

Gadikota ve ark. (17) koronal düzlemdeki fermoral tünel eğikliği ile ilgili olarak, transtibial teknik grubunda oblisitenin AM portal grubundan daha fazla olduğunu göstermiştir $\left(59.0^{\circ} \pm 8.0^{\circ}\right.$ vs $\left.38.0^{\circ} \pm 6.0^{\circ}\right)$. Panni ve ark. (18) transtibial gruptaki değerin Outside In grubundan daha yüksek olduğunu bildirmiştir $\left(65.4^{\circ} \pm 7.6^{\circ}\right.$ $\left.42.2^{\circ} \pm 7.9^{\circ}\right)$. Bu çalışmalar sonucunda femoral tünel oblisitesi düşük olan gruplarda klinik ve fonksiyonel olarak daha başarılı neticeler elde edilmiștir. Biz de literatürle uyumlu olarak femoral tünel oblisitesini düşük bulduk. Transtibial teknikte femoral tünel oluşturmanın tibia tarafindan yönlendirildiği gösterilmiştir. Hefzy ve arkadaşları (19) yaptıkları çalışmalar sonrasında anatomik olmayan tibial ve femoral tünel yerleşimi ÖÇB greft yetmezliğinin en önemli sebeplerinden birisi olduğunu söylemişlerdir. ÖÇB tamirinde femoral tünel cerrahi başarının en önemli etmenlerindendir. Greftin ideal olarak fonksiyon görebilmesi için femoral tünel femurun posterior korteksine en az $2 \mathrm{~mm}$ kalacak şekilde ve inferiorda yerleştirilmelidir. Shantanu K ve arkadaşları (20) yaptıkları bir çalışmada all inside tekniğin anatomik teknikten daha üstün olduğunu bildirmişlerdir. Fakat yapılan çalışmaların büyük bölümünde revizyon yapılan vakaların çoğunda femoral tespitin daha ön ve superiorda olduğu görülmekte ve greft yetmezliğinin en önemli 
nedeni olarak belirtilmektedir (20-22). Biz de bütün ÖÇB rekonstrüksiyonlarımızda TT tekniğinin anatomik olmadığını ve başarılı ÖÇB rekonstrüksiyonu gerçekleştirmediğini düşünerek aksesuar anteromedial portal kullanarak ilk önce femoral tünel oluşturduk.

Anatomik ÖÇB rekonstrüksiyonu için femoral tünel yerleşimi kadar tibial tünelin ideal yerleşimde olması da önemlidir. Tibial tünelin ideal yerleşimi için çeşitli görüşler olmakla birlikte en çok Jackson ve Gasser (23) tarafından belirtilen anatomik kılavuz noktalarının belirlenmesine dayalı sistem kullanım alanı bulmuştur. $\mathrm{Bu}$ k1lavuz noktalar lateral menisküs, arka çapraz bağ ve medial eminens olarak değerlendirilmiştir. Takeda ve arkadaşları (24) transtibial teknik koronal düzlemdeki fermoral tünel oblisitesini AM portal uygulanan gruba göre daha yüksek olduğunu göstermiştir.

Taketomi ve ark. (25) ise femoral tesbitte endobutton kullanarak K-P-K greftini tespit etmiş olup femoral fiksasyon için güvenilir olduğunu tespit etmiştir. Bizim çalışmamızda ki tüm hastalara femoral tesbit için EB-CL kullandık. Kolay uygulanabilmesi ve güvenilir olmasının diğer femoral tespit yöntemlerine göre en önemli avantajı olduğunu düşünmekteyiz.

Klein ve ark. (26) çalışmasında, greftin tibial tespitinde Vida-Staple'in diğer tespit yöntemlerine göre daha şiddetli güçlerde bile daha dayanıklı olduğu gözlenmiştir. Biz tibial tespitlerimizi yaparken, dizi 30-45 derece kadar fleksiyon pozisyonunda tutmaya çalıştık ve greft gerilimi yüksek tonusta iken tespitimizi gerçekleştirdik. Biz çalışmamızda tibial tünel fiksasyonunda, bütün hastalarımıza biyobozunur vida ve U çivisi kullanarak tibia fiksasyonunu gerçekleştirdik.

Ön çapraz bağ rekonstrüksiyonlarının fonksiyonel sonuçlarını değerlendirmek için yaygın olarak Lysholm ve Tegner aktivite skorları, IKDC diz bağları değerlendirme formu, Cincinnati aktivite skorlamaları kullanılmaktadır (27). Bu çalışmada izlem sonrası Lysholm skoru ortanca değeri (88 [Q1-Q3: 86-97.75]) ve Tegner aktivite skoru ortanca değeri (7[Q1-Q3:6-7])) ameliyat öncesi değerlerle (40 [Q1-Q3: 38-44]), 6[Q1Q3:5-6])) karşılaştırıldığında istatistiksel açıdan ileri derecede anlamlı farklılıklar bulundu ( her biri için $\mathrm{p}<0.001)$.

IKDC skorlamasına göre 41 hasta $(\% 64.06) \mathrm{A}, 21$ hasta (\%32.81) B ve 2 hasta (\%3.12) C grubunda yer almıştır. On yıllık takip bildirilen bir çalışmada hastaların toplam \%86'sının A ve B grubunda olduğu (28), başka bir çalışmada ise 64 hastanın 56'sinin A veya B grubunda olduğu ortaya konulmuştur (29). Biz de literatürle uyumlu sonuçlar elde ettik.

ÖÇB cerrahisinde başarılı sonuçlar için cerrahi kadar rehabilitasyon da pay sahibidir. Howell ve Taylor (30) uygun rehabilitasyon programıla hastaların 4-6 ay sonra spora dönebileceklerini belirtmişlerdir. Çalışmamızda hastalarımıza kendilerinin yapması gereken egzersizleri postop en kısa sürede başladık.

Ortalama 3 ile 4. haftalar arasında fizik tedavi almalarını sağladık. Ortalama mücadele sporlarına literatürün aksine 7 ile 9. aylarda dönmelerine izin verdik.

Literatürlerde aynı değerlendirme kriterlerini kullanan ve otojen hamstring tendonlarıyla yapılan anatomik ÖÇB rekonstrüksiyonlarının takip sonuçlarının bizim sonuçlarımızla benzerlik gösterdiğini gördük. Bizim çalışmamızda dâhil edilen hastalarımızın 3 tanesinde halen spor esnasında dizde hafif ağrı tarif ederken, 1 hastamizda halen tibial insizyon yerinde hipoestezi bulunmaktadır. Çalışmamızda, hastalarımızın orta dönem sonuçları mevcut olup, ÖÇB rekonstriksüyonu sonrası osteoartrit gelişimi açısından uzun dönem takibi gerektiği kanaatindeyiz. ÖÇB rekonstrüksiyonu sonrası rekonstrükte bağda meydana gelebilecek değişikliklerin, komplikasyonların ve bunun sonucunda oluşabilecek diz instabilitesinin değerlendirilmesi açısından hastaların yeterli takibi gereklidir.

\section{SONUÇ}

Ön çapraz bağ rekonstrüksiyonu yapılırken ÖÇB anatomisine en uygun femoral tünel oblisitesinin oluşturulması ön-arka stabilitenin yanında rotasyonel stabiliteyi de önemli oranda artırmaktadır. Eski anatomisine uygun olan başarılı bir cerrahinin yeterli fizik tedavi ile desteklendiği olgularda klinik ve fonksiyonel sonuçların başarısı tatmin edici düzeydedir. Femoral tünel başlangıç noktasının değerlendirilmesi ile ilgili çok sayıda çalışma bulunmasına rağmen femoral tünel eğimi ile ilgili prospektif çalışmaların literatüre katk1 sunacağ1 düşüncesindeyiz.

$\mathrm{Bu}$ çalışmanın sınırlamalarından biri, $14.5 \pm 7.4$ ay arasında değişen nispeten kısa takip süresidir. Diz ekleminin stabilitesinin daha doğru değerlendirilebilmesi için 5 yıldan fazla takip gerektiğine inanıyoruz.

\section{KAYNAKLAR}

1. Woo SLY, Fox RJ, Sakane M, Livesay GA, Rudy TW, Fu FH. Biomechanics of the ACL: Measurements of in situ force in the ACL and knee kinematics. The Knee. 1998; 5(4): 267-88.

2. Reinhardt KR, Hetsroni I, Marx RG. Graft selection for anterior cruciate ligament reconstruction: A level I systematic review comparing failure rates and functional outcomes. Orthop Clin North Am. 2010; 41(2): 249-62.

3. Çetinkaya E, Mutlu H, Yavuz U, Gül M, Çetin Ü, Özkaya U. Anteromedial portal tekniği ile tek demet anatomik ön çapraz bağ rekonstrüksiyonu sonuçlarımız. Jarem. 2016; 6(2): 88-93.

4. Noyes FR, Keller CS, Grood ES, Butler DL. Advances in the understanding of knee ligament injury, repair, and rehabilitation. Med Sci Sports Exerc. 1984; 16(5): 427-43.

5. Calas P, Dorval N, Bloch A, Argenson JN, Parratte S. A new anterior cruciate ligament reconstruction fixation technique (quadrupled semitendinosus anterior cruciate ligament reconstruction with polyetheretherketone cage fixation). Arthrosc Tech. 2012; 1(1): e47-52.

6. Darren J, Todd S, James I, Fu FH, Harner CD. Revision anterior cruciate ligament surgery: Experience from pittsburgh. Clin Orthop Relat Res. 1996; 325(2):100-9.

7. Dei Giudici L, Fabbrini R, Garro L, Arima S, Gigante A, Tucciarone A. Arthroscopic transphyseal anterior cruciate ligament reconstruction in adolescent athletes. J Orthop Surg (Hong Kong). 2016; 24(3): 307-11. 
8. Shelbourne KD, Patel DV. Timing of surgery in anterior cruciate ligament injured knees. Knee Surg Sports Traumatol Arthrosc. 1995; 3(3): 148-56.

9. Shelbourne KD, Gray T. Results of anterior cruciate ligament reconstruction based on meniscus and articular cartilage status at the time of surgery. Fiveto fifteen-year evaluations. Am J Sports Med. 2000; 28(4): 446-52.

10. Levy BA, Dajani KA, Whelan DB, Stannard JP, Fanelli GC, Stuart MJ, et al. Decision making in the multiligamnet -injured knee:an evidence-based systematic review. Arthroscopy. 2009; 25(4): 430-8.

11. Gupta R, Bahadur R, Malhotra A, Masih GD, Gupta P. Anterior cruciate ligament reconstruction using hamstring tendon autograft with preserved insertions. Arthrosc Tech. 2016; 5(2): e269-74.

12. Darnley JE, Léger-St-Jean B, Pedroza AD, Flanigan DC, Kaeding CC, Magnussen RA. Anterior cruciate ligament reconstruction using a combination of autograft and allograft tendon: A moon cohort study. Orthop J Sports Med. 2016; 4(7): 2325967116662249.

13. Vaishya R, Agarwal AK, Ingole S, Vijay V. Current trends in anterior cruciate ligament reconstruction: A Review. Cureus. 2015; 7(11): e378. doi: 10.7759/cureus.378. Review.

14. Musil D, Sadovsky P, Filip L, Vodicka Z, Stehlík J. Anterior cruciate ligament reconstruction using hamstring tendon autograft with reserved insertions. Arthrosc Tech. 2016; 5(2): 269-74

15. Luo H, Yu JK, Ao YF, Yu CL, Peng LB, Lin CY, et. al. Relationship between different skin incisions and the injury of the infrapatellar branch of the saphenous nerve during anterior cruciate ligament reconstruction. Chin Med J (Engl). 2007; 120(13): 1127-30.

16. Wolf MR, Murawski CD, van Diek FM, van Eck CF, Huang Y, Fu FH. Intercondylar notch dimensions and graft failure after single-and double-bundle anterior cruciate ligament reconstruction. Knee Surg Sports Traumatol Arthrosc. 2015; 23(3): 680-6.

17. Gadikota HR, Sim JA, Hosseini A, Gill TJ, Li G. The relationship between femoral tunnels created by the transtibial, anteromedial portal, and outside-in techniques and the anterior cruciate ligament footprint. Am J Sports Med. 2012; 40(4): 882-8.

18. Panni AS, Milano G, Tartarone M, Demontis A, Fabbriciani C. Clinical and radiographic results of ACL reconstruction: A 5 to 7 year follow-up study of outside in versus insideout reconstruction techniques. Knee Surg Sports Traumatol Arthrosc. 2001; 9(2): 77-85.

19. Hefzy MS, Grood ES, Noyes FR. Factors affecting the region of most isometric femoral attachments. Part II: the anterior cruciate ligament. Am J Sports Med. 1989; 17(2): 208-16.

20. Shantanu K, Kushwaha SS, Kumar D, Kumar V, Singh S, Sharma V. A Comparative study of the results of the anatomic medial portal and all-inside arthroscopic ACL reconstruction. J Clin Diagn Res. 2016; 10(11): RC01-3.

21. Harner CD, Giffin JR, Dunteman RC, Annunziata CC, Friedman MJ. Evaluation and treatment of recurrent instability after anterior cruciate ligament reconstruction. Instr Course Lect. 2001; 50(1): 46374.

22. Allen Cr, Giffin JR, Harner CD. Revision anterior cruciate ligament reconstruction. Orthop Clin North Am. 2003; 34(1): 79-98.

23. Jackson DW, Gasser SI. Tibial tunnel placement in ACL reconstruction. Arthroscopy. 1994; 10(2): 12431.

24. Takeda Y, Iwame T, Takasago T, Kondo K, Goto T, Fujii K, et al. Comparison of tunnel orientation between transtibial and anteromedial portal techniques for anatomic double-bundle anterior cruciate ligament reconstruction using 3-dimensional computed tomography. Arthroscopy. 2013; 29(2): 195-204.

25. Taketomi S, Inui $H$, Nakamura $K$, Yamagami R, Tahara K, Sanada T, et. al. Secure fixation of femoral bone plug with a suspensory button in anatomical anterior cruciate ligament reconstruction with bonepatellar tendon-bone graft. Joints. 2016; 3(3):102-8.

26. Klein JP, Linter DM, Downs D, Vavrenka K. The incidence and significance of femoral tunnel widening after quadrupled hamstring anterior cruciate ligament reconstruction using femoral cross pin fixation. Arthroscopy. 2003; 19(5): 470-76.

27. Mologne TS, Friedman MJ. Anterior cruciate ligament reconstruction with bone-patella tendonbone autograft: Indications, technique, complications, and management. In: Insall JN, Scott WN, editors. Surgery of the knee. Philadelphia: Churchill Livingstone; 2001. p. 681-93.

28. van der Hart CP, van den Bekerom MP, Patt TW. The occurrence of osteoarthritis at a minimum of ten years after reconstruction of the anterior cruciate ligament. J Orthop Surg. 2008; 3: 1-9. doi:10.1186/1749-799X-324.

29. Değirmenci E, Yücel İ, Özturan K. Hamstring tendon otogrefti ile ön çapraz bağ rekonstrüksiyonu. Bakırköy Tıp Dergisi. 2010; 6(1): 29-34.

30. Howell SM, Taylor MA. Brace-free rehabilitation, with early return to activity, for knees reconstructed with a double-looped semitendinosus and gracilis graft. J Bone Joint Surg Am. 1996; 78(6): 814-25. 